Original Research Article

\title{
A retrospective study to evaluate the pattern of spontaneously reported antiretroviral induced adverse drug reactions in a tertiary care hospital
}

\author{
Swati V. Patil*, Sudhir R. Pawar
}

Department of Pharmacology, Lokmanya Tilak Municipal Medical College, Sion, Mumbai, Maharashtra, India

Received: 21 March 2018 Accepted: 30 March 2018

*Correspondence to:

Dr. Swati V. Patil, Email: drswati246@gmail.com

Copyright: (C) the author(s), publisher and licensee Medip Academy. This is an openaccess article distributed under the terms of the Creative Commons Attribution NonCommercial License, which permits unrestricted noncommercial use, distribution, and reproduction in any medium, provided the original work is properly cited.

\begin{abstract}
Background: To evaluate the adverse effect profile of spontaneously reported cases of adverse drug reactions due to antiretroviral (ART) drugs in a tertiary care teaching hospital.

Methods: A descriptive retrospective study of pattern of ART induced adverse drug reactions (ADRs) spontaneously reported to the Pharmacology department at a tertiary care hospital from January 2011 to December 2016. The details of suspected ADRs including drugs involved, treatment given for ADRs, and the outcome were also documented. These ADRs were analyzed for causality (WHO scale), severity (Hartwig et al. scale), seriousness (ICH E 2A guidelines), preventability (Schumock and Thornton scale) and type based on Edwards and Aronson classification system.

Results: Of the 75 cases of ART induced ADRs, reactions were slightly more common in males (52\%) and had median age and duration of ART as 36 years and 109 days respectively. Drug induced anemia was the most common presentation followed by cutaneous ADR and zidovudine being the commonest offender. Severity was moderate in $85.3 \%$ and causality was probable in $16 \%$ and possible in $84 \%$ cases. The type reaction was augmented type in $41.3 \%$ and not preventable in $76 \%$.

Conclusions: Zidovudine is the commonest drug implicated in causing anemia amongst the antiretrovirals. Spontaneous reporting method for antiretroviral pharmacovigilance is insufficient. Targeted spontaneous reporting or cohort event monitoring need to be studied for antiretroviral pharmacovigilance.
\end{abstract}

Keywords: Antiretrovirals, spontaneously reporting, Targeted spontaneous reporting

\section{INTRODUCTION}

Growing socio-economic burden of acquired immunodeficiency syndrome (AIDS) in India led to the inception of National AIDS Control Organization (NACO) in the year 1986 and subsequently in the formation of National AIDS program in the year 1987. Antiretroviral therapy (ART) became the keystone of National AIDS program. Highly active antiretroviral therapy (HAART) presently is a lifelong therapy. ${ }^{1}$

The first-line ART consist of the generic, fixed-dose combination (FDC) regimen of stavudine (d4T) or zidovudine (AZT) plus lamivudine (3TC) and nevirapine (NVP) or efavirenz (EFV), although tenofovir disoproxil fumarate (TDF) plus 3TC or emtricitabine (FTC) and NVP or EFV combination regimens are also used. The secondline ART comprises the protease inhibitors (ritonavirboosted lopinavir (LPV/r)) plus TDF/FTC plus either AZT, d4T, or didanosine (ddl). ${ }^{2}$

The well-known drug toxicities include bone marrow suppression (zidovudine [AZT]), pancreatitis (didanosine), hypersensitivity (abacavir), hepatic necrosis (nevirapine [NVP]), neuropsychiatric complaints (efavirenz), and nephrolithiasis (indinavir). ${ }^{3}$ 
Moreover, drug-related toxicity is being increasingly recognized because of the declining incidence of HIV1associated opportunistic infection. The risk of specific side effects varies from drug to drug, from drug class to drug class, and from patient to patient. ${ }^{4}$ Although the primary therapeutic goals of ART are to achieve and maintain viral suppression and improve patient immune function, among the secondary goals should be to select a safe and effective regimen, taking into account individual patients, underlying conditions, concomitant medications, and history of drug intolerance. ${ }^{5}$

In India, the National AIDS Control Organization (NACO) introduced inexpensive and generic ART drugs. ${ }^{6}$ So, with the availability of generic HAART at low cost, an increasing number of HIV-infected individuals in India are now receiving therapy. ${ }^{7}$ There is a clear and growing need to better understand the benefits and risks of antiretrovirals under conditions of actual use. Most questions of drug safety may only be answered by observing and analyzing the use and outcomes of therapy in large populations during the post-approval phase.

Spontaneous adverse drug reaction (ADR) reporting may be defined as a scheme for collating individual case reports of clinical suspicions of adverse drugs reaction operated for the primary purpose of detecting unknown serious potential drug toxicity. Spontaneous ADR reporting has become the cornerstone of post-marketing safety monitoring and extensive systems are in operation around the world. ${ }^{8}$

Our institute is a recognized ADR monitoring centre (AMC) since 2011, so on these grounds this study was planned to evaluate the profile of ART induced ADRs spontaneously reported to the pharmacovigilance cell by the clinical departments. The study also tries to ascertain whether only spontaneous reporting suffice to screen adverse drug reactions to the used antiretrovirals.

\section{METHODS}

This retrospective descriptive study analyzed individual case safety reports (ICSRs) in HIV-positive patients receiving ART between January 2011 and December 2016 in a tertiary care hospital.

The data elements to be studied were obtained from the central drug standard control organization (CDSCO) forms. Data regarding demographic details, medical history, details of human immunodeficiency virus (HIV) infection including most recent CD4 count, details of antiretroviral therapy (ART) collected from patient's records. Results of laboratory investigations done were also noted. The details of suspected ADRs including drugs involved, treatment given for ADRs, and the outcome were also documented. These ADRs were analyzed for causality (WHO scale), severity (Hartwig et al. scale), seriousness (ICH E 2A guidelines), preventability (Schumock and Thornton scale) and type based on Edward and Aronson classification system. The data was also screened for presence of established risk factors like age gender, comorbid conditions and concomitant medications. The results are expressed as frequency of events in percentage form.

\section{RESULTS}

Total spontaneously reported antiretroviral induced ADR cases reported are 75 out of 1200 reported cases during January 2011 to December 2016. The baseline characteristics of these are presented in the Table $1.69 \%$ of cases were reported from medicine department followed by $24 \%$ from pediatrics and $5 \%$ from dermatology department. The clinical presentation as per MedRa Soc and spectrum of ADR is shown in Table 2 and 3 respectively. The frequency of suspected antiretroviral drugs is depicted graphically in Figure 1. Other parameters pertaining ADR are presented in Table 4 . The co-infection of tuberculosis was seen in $6.6 \%$ of the ADR cases and cotrimoxazole was concomitant medication in $20 \%$ while few were on antitubercular (6.6\%) and antidiabetic therapy.

Table 1: Baseline characteristics $(n=75)$.

\begin{tabular}{|lll|}
\hline Age & $\mathbf{n}$ & $\%$ \\
\hline Less than 20 yrs & 26 & $3 \%$ \\
\hline 21 to 40 years & 49 & $6 \%$ \\
\hline Mean Age (yrs) & $31.58 \pm 16.26$ & \\
\hline Median Age (yrs) & $\begin{array}{l}36 \text { (Min-5 } \\
\text { Max 60) }\end{array}$ & \\
\hline Gender & $\mathbf{n}$ & $\mathbf{\%}$ \\
\hline Males & 39 & $5 \%$ \\
\hline Females & 36 & $4 \%$ \\
\hline Reporting departments & $\mathbf{n}$ & $\mathbf{\%}$ \\
\hline Medicine & 52 & $6 \%$ \\
\hline Pediatrics & 18 & $2 \%$ \\
\hline Dermatology & 5 & $7 \%$ \\
\hline ART Regimes & $\mathbf{n}$ & $\mathbf{\%}$ \\
\hline $\begin{array}{l}\text { Zidovudine+Lamivudine } \\
\text { +Nevirapine }\end{array}$ & 49 & $6 \%$ \\
\hline $\begin{array}{l}\text { Zidovudine } \\
\text { +Lamivudine+Efavirenz }\end{array}$ & 12 & $1 \%$ \\
\hline $\begin{array}{l}\text { Tenofovir } \\
\text { +Lamivudine+Nevirapine }\end{array}$ & 3 & $4 \%$ \\
\hline $\begin{array}{l}\text { Tenofovir+Lamivudine+ } \\
\text { Efavirenz }\end{array}$ & 9 & $1 \%$ \\
\hline $\begin{array}{l}\text { Abacavir + } \\
\text { Lamivudine+Nevirapine }\end{array}$ & 1 & $1 \%$ \\
\hline Abacavir+Lamivudine+Lopinavir & 1 & \\
\hline
\end{tabular}

\section{DISCUSSION}

Highly active antiretroviral therapy is becoming increasingly effective but also increasingly complex. The adverse effects of antiretroviral therapy may cause symptoms affecting a variety of organ systems. Although 
current antiretroviral regimens are potent from an antiviral perspective, they often fail because of patient non adherence. To optimize adherence, and hence efficacy, clinicians must focus on preventing adverse effects. ${ }^{9}$

Table 2: Clinical presentation of the case as per medical dictionary for drug regulatory affairs system organ class (MedDRa SoC) $(n=75)$.

\begin{tabular}{|lll|}
\hline System organ class & n & $\%$ \\
\hline Blood and lymphatic system disorders & 34 & $45 \%$ \\
\hline Cardiac disorders & 1 & $1 \%$ \\
\hline Gastrointestinal disorders & 3 & $4 \%$ \\
\hline Hepatobiliary disorders & 9 & $12 \%$ \\
\hline Nervous system disorders & 2 & $3 \%$ \\
\hline Renal and urinary disorders & 7 & $9 \%$ \\
\hline Skin and subcutaneous tissue disorders & 19 & $26 \%$ \\
\hline
\end{tabular}

Table 3: Spectrum of adverse drug reactions reported $(n=75)$.

\begin{tabular}{|ll|}
\hline Spectrum & n \\
\hline Drug induced Anemia & 31 \\
\hline Drug induced Pancytopenia & 3 \\
\hline Drug induced Renal Failure & 7 \\
\hline Drug induced Pancreatitis & 3 \\
\hline Drug induced Hepatotoxicity & 6 \\
\hline Drug induced Rash & 18 \\
\hline Drug induced Peripheral Neuropathy & 1 \\
\hline Drug induced Nausea and Vomitting & 3 \\
\hline Drug induced Dizziness & 1 \\
\hline Drug induced Cardiomyopathy & 1 \\
\hline Drug induced Nail Hyperpigmentation & 1 \\
\hline
\end{tabular}

The retrospective analysis of all the cases spontaneously reported from January 2011 to December 2016 to the pharmacovigilance cell showed that 75 reactions which were reported were attributed to antiretroviral drugs. Out of these 75 reactions, the median age of the patients was 36 years (Min-5, Max 60), where $65 \%$ of these belonged to the age group of 21 to 40 years. The adverse drug reactions had slight male preponderance i.e. $52 \%$ in males as compared to $48 \%$ in females. The commonest regime which was found to be associated with ADRs was zidovudine+lamivudine+nevirapine $(66 \%)$ followed by zidovudine+lamivudine+efavirenz $(16 \%)$. This is similar to the findings of Bhuvana et al, study conducted in a tertiary care hospital in Mysore. ${ }^{10}$ The popularity of these regimens might be due to their availability and accessibility as cheap, generic, once daily FDC tablets, which may have contributed to the reluctance of most HIV programs in resource poor countries to use of stavudinebased regimens. ${ }^{11}$

The organ system which was commonly involved was blood and lymphatic system i.e. $45 \%$ followed by skin and subcutaneous tissue i.e. $26 \%$ and hepatobiliary in $12 \%$. Drug induced anemia was the commonest adverse drug reaction. Amongst the cutaneous ADRs maculopapaular rash was seen in 17 cases and Steven Johnson syndrome in 1 case. The suspected drug in most of the reactions was zidovudine $(\mathrm{n}=25)$ causing anemia followed by lamivudine $(n=28)$ and nevirapine $(n=) 13$. There were also 11 cases of renal failure due to tenofovir in tenofovir based regimes $(16 \%)$. In a another study done by Rather et al, common adverse effects observed included anemia $(58.6 \%)$, pruritus (23.2\%), skin rash (18.2\%), hypertriglyceridemia $(15.2 \%)$, and hepatitis (60.6\%), peripheral neuropathy $(14.1 \%){ }^{12}$ The most common ADRs recorded were cutaneous $(44.4 \%)$ followed by hematological $(32.2 \%)$, neurological $(31.1 \%)$, metabolic $(22.2 \%)$ and gastrointestinal $(20 \%)$ in a study conducted by Sharma et al. ${ }^{4}$

Table 4: Details of ADR $(n=75)$.

\begin{tabular}{|ll|}
\hline Seriousness $\mathbf{n}(\%)$ & $63(84 \%)$ \\
\hline Yes & $12(16 \%)$ \\
\hline No & \\
\hline Severity n (\%) & $10(13.3 \%)$ \\
\hline Mild & $64(85.3 \%)$ \\
\hline Moderate & $1(1 \%)$ \\
\hline Severe & $109(\mathrm{Min}-2$, \\
\hline $\begin{array}{l}\text { Duration of ART therapy } \\
\text { Median days (range in days) }\end{array}$ & Max-2670) \\
\hline Outcome n (\%) & $9(12 \%)$ \\
\hline Recovered & $52(69.3 \%)$ \\
\hline Recovering & $9(12 \%)$ \\
\hline Continuing & $2(2.6 \%)$ \\
\hline Fatal & $3(2.6 \%)$ \\
\hline Unknown & \\
\hline Causality n $(\%)$ & $12(16 \%)$ \\
\hline Probable & $63(84 \%)$ \\
\hline Possible & \\
\hline Preventability n (n\%) & $18(24 \%)$ \\
\hline Yes & $57(76 \%)$ \\
\hline No & $31(41.3 \%)$ \\
\hline Type of ADR n $(\%)$ & $20(26.6 \%)$ \\
\hline Type A & $24(32 \%)$ \\
\hline Type B & \\
\hline Type C & \\
\hline
\end{tabular}

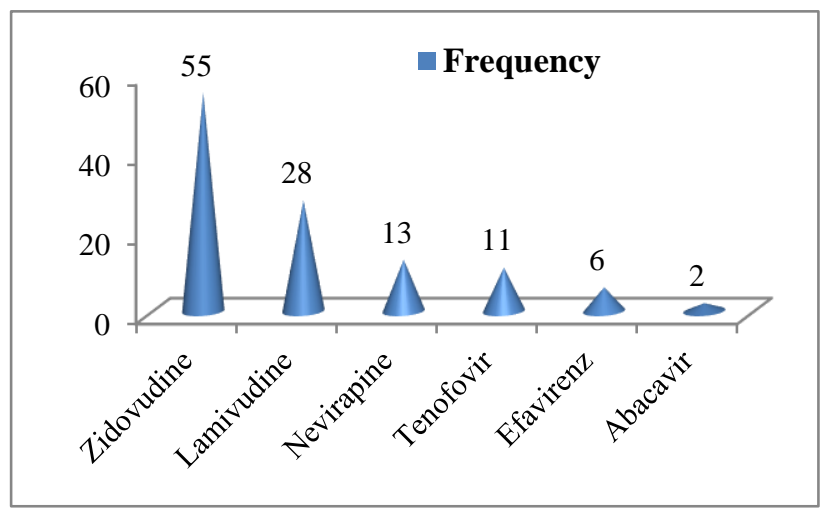

Figure 1: Suspected antiretroviral (ARV) drugs $(n=75)$. 
Due to high rates of ARV-related ADRs, South Africa patients are now using Tenofovir (TDF) containing regimen as a first line ARV treatment. ${ }^{13}$ In a study by Agu et al, of the reported ADRs, 63.2\%, 8.2\% and $19.3 \%$ occurred in patients on zidovudine-based, stavudine-based and tenofovir-based regimens, respectively. ADRs were found to be less likely to occur in patients on stavudinebased and tenofovir-based regimens compared to zidovudine-based regimens. ${ }^{14}$ Initial ART regimens containing tenofovir are equivalent to those containing zidovudine pertaining outcomes of virologic response and serious adverse events. However, tenofovir is superior to zidovudine in terms of immunologic response and adherence and less frequent emergence of resistance. How much the other drugs in the regimens contributed to these findings is unclear, and true head-to-head trials are still warranted. The role of each drug in initial ART likely will be driven by their specific toxicities. ${ }^{15}$

The reaction was serious in $84 \%$ of the reported cases whereas mild (13.3\%), moderate $(83.3 \%)$ and severe $(1 \%)$ in severity as per Hartwig Seigel scale. These findings were comparable to a retrospective analysis done by Anwikar et al, where $8.77 \%$ were mild, $77.19 \%$ were moderate and $14.02 \%$ were severe in nature. Whereas $80.26 \%$ ADRs were found to be non-serious whereas 45 $(19.74 \%)$ were serious. ${ }^{16}$ The outcome of reaction was reported to be recovering in $69.3 \%$ of them after discontinuation of the offending drug. It was reported to be recovered and continuing in $12 \%$ of cases. The reaction proved to be fatal in a case of interstitial nephritis due to tenofovir.

The causal association was possible for $84 \%$ of the reactions and probable in $16 \%$ of them. Most of the reactions were of not preventable type in $76 \%$. These findings were similar to those observed in Bhuvana et al, study where causality was possible in $89.24 \%$ and also only $30.38 \%$ patients ADRs were preventable. ${ }^{10}$ As also demonstrated by Mehta et al, study most of the ARVrelated ADRs are often inevitable and unpredictable, which makes treatment of these ADRs problematic. ${ }^{17}$

The classification of adverse reactions based on Edwards and Aronson classification was of augmented type in $41.3 \%$, chronic in $32 \%$ and idiosyncratic in nature in $26.6 \%$. These findings were same as observed in a study done by Sadiq et al in patients on antiretroviral with concomitant antitubercular therapy. ${ }^{18}$ Agu et al, found $50 \%$ of ADRs were reported by patients who were taking cotrimoxazole concomitantly with antiretroviral drugs (ARVs). ${ }^{14}$ In this study, cotrimoxazole was concomitant drug in $20 \%$ of cases. The effect of this on occurrence of ADRs should be evaluated.

This study being retrospective analysis of spontaneously reported ART induced ADRs had limitations due to under reporting, insufficient data to find association of risk factors with reactions and also difficulties while assessing preventability as some data and investigation related information could not be traced. In Sharma et al, study ADRs were observed in 64 out of 90 patients taking antiretroviral study whereas in this study adverse reactions voluntary reported were only 74 antiretroviral induced reactions out of 1200 reported ADRs. ${ }^{4}$ This demonstrates profound under reporting and inadequacy pertaining pharmacovigilance of antiretroviral drugs. Spontaneous reporting (SR) of ADR is the foundation of national and international drug safety evaluation after licensing and approval for use in general population. ${ }^{19}$ It is a more popular method of pharmacovigilance, administratively simpler, covers potentially large and diverse population, and good for the identification of rare, serious drug-related or delayed adverse effects of medicines compared to cohort event monitoring. ${ }^{20}$ However, under-reporting and strong biases in reporting are major problems with spontaneous reporting system (SR). ${ }^{19}$

There is a need to bridge the gap between AMCs and ART centres in monitoring and reporting ADRs with the use of ART drugs. This could be addressed by regular interactive session and meetings for better coactions and to harmonize the process of ADR reporting. Integration of Pharmacovigilance Programme of India (PvPI) with National AIDS Control Programme gives a scope of performing cohort event monitoring (CEM) for the earliest possible recognition of new ADRs of ART drugs including interactions, benefit-risk assessment of different ART regimens or products and evidence based regulatory action. In CEM, all adverse events occurring to a patient taking ART are collected regardless of the causality or relationship with the ART drugs. ${ }^{21}$ The advantages of CEM over spontaneous reporting include the ability to produce rates, rapid results, and early detection of signals, fewer missing data and less reporting bias. ${ }^{22}$ However, CEM requires more resources than spontaneous reporting. Another novel pharmacovigilance method called "targeted spontaneous reporting", (TSR) builds on SR by adding aspects of CEM. In this method, a sub-group of patients is defined and ADRs are monitored in this cohort as part of routine care. An advantage of TSR is that it can capture measurements over the entire length of the treatment. It can also be adapted to capture all ADRs, only ADRs relevant to the medication of interest, or continual general pharmacovigilance data. ${ }^{23}$ This TSR has been tried for antiretrovirals in a study conducted by Rachlis et al. ${ }^{24}$

\section{CONCLUSION}

Thus, sensitizing all the health care providers for reporting adverse drug reactions is of rpime importance. There is a need to develop collateral methods for building up database pertaining ADRs with special drug groups like antiretrovirals which need systematic evaluation for feasibility.

\author{
Funding: No funding sources \\ Conflict of interest: None declared \\ Ethical approval: The study was approved by the \\ Institutional Ethics Committee
}




\section{REFERENCES}

1. Nadkar MY, Bajpai S. Antiretroviral therapy: toxicity and adherence. $\mathrm{J}$ Assoc Physicians India. 2009;57:375-6.

2. Castelnuovo B, John L, Lutwama F, Roland A, Spacek LA. Three-year outcome data of second-line antiretroviral therapy in Ugandan adults: Good virological response but high rate of toxicity. J Int Assoc Physicians AIDS Care (Chic). 2009;8:52-59.

3. Singh H, Dulhani N, Tiwari P, Singh P, Sinha T. A prospective, observational cohort study to elicit adverseeffects of antiretroviral agents in a remote resource-restricted tribal population of Chhattisgarh. Indian J Pharmacol. 2009;41(5):224-6.

4. Sharma A, Vora R, Modi M, Sharma A, Marfatia Y. Adverse effects of antiretroviral treatment. Indian J Dermatol Venereol Leprol. 2008;74:234-7.

5. Jena A, Sachdeva RK, Sharma A, Wanchu A. Adverse drug reactions to nonnucleoside reverse transcriptase inhibitor-based antiretroviral regimen: a 24-week prospective study. J Int Assoc Physicians AIDS Care (Chic). 2009;8(5):318-22.

6. Pattanapanyasat K, Thakar MR. CD4+T cell count as a tool to monitor HIV progression and anti-retroviral therapy. Indian J Med Res. 2005;121:539-49.

7. Kumarasamy N, Vallabhaneni S, Cecelia AJ, Yepthomi T, Balakrishnan P, Saghayam S, et al. Reasons for Modification of Generic Highly Active Antiretroviral Therapeutic Regimens Among Patients in Southern India. J Acquir Immune Defic Syndr. 2010;41:53-8.

8. Waller PC. Making the most of spontaneous adverse drug reaction reporting. Basic Clin Pharmacol Toxicol. 2006;98(3):320-3.

9. Rajesh R, Vidyasagar S, Patel N. Safety aspects of Antiretroviral therapy for management of HIV Infection. J basic clinical pharmacy. 2010;1(1):47-53.

10. Bhuvana KB, Hema NG, Sangeetha. A prospective observational study of adverse drug reactions to antiretroviral therapy: type and risk factors in a tertiary care teaching hospital. Int J Basic Clin Pharmacol. 2014;3:380-4.

11. Laurent C, Bourgeois A, Mpoudi-Ngole E, Ciaffi L, Kouanfack C, Mougnutou R, et al. Tolerability and effectiveness of first-line regimens combining nevirapine and lamivudine plus zidovudine or stavudine in Cameroon. AIDS research and human Retroviruses. 2008;24(3):393-400.

12. Rather ZA, Chowta MN, Prakash Raju GJ, Mubeen F. Evaluation of the adverse reactions of antiretroviral drug regimens in a tertiary care hospital. Indian $\mathbf{J}$ Pharmacol. 2013;45(2):145-8.

13. Masenyetse LJ, Manda SO, Mwambi HG. An assessment of adverse drug reactions among HIV positive patients receiving antiretroviral treatment in South Africa. AIDS Res Ther. 2015;12:6.

14. Agu KA, Oparah AC. Adverse drug reactions to antiretroviral therapy: Results from spontaneous reporting system in Nigeria. Perspectives Clinical Research. 2013;4(2):117-24.

15. Spaulding A, Rutherford GW, Siegfried N. Tenofovir or zidovudine in three-drug combination therapy with one nucleoside reverse transcriptase inhibitor and one non-nucleoside reverse transcriptase inhibitor for initial treatment of HIV infection in antiretroviralnaïve individuals. Cochrane Database Syst Rev. 2010;(10):CD008740.

16. Anwikar SR, Bandekar MS, Smrati B, Pazare AP, Tatke PA, Kshirsagar NA. HAART induced adverse drug reactions: a retrospective analysis at a tertiary referral health care center in India. Int J Risk Saf Med. 2011;23(3):163-9.

17. Mehta U, Durrheim DN, Blockman M, Kredo T, Gounden R, Barnes KI. Adverse drug reactions in adult medical inpatients in a South African hospital serving a community with a high HIV/AIDS prevalence: prospective observational study. Br J Clin Pharmacol. 2008;65:396-406.

18. Sadiq S, Khajuria V, Tandon VR, Mahajan A, Singh JB. Adverse Drug Reaction Profile in Patients on Antitubercular Treatment Alone and in Combination with Highly Active Antiretroviral Therapy. J Clin Diagn Res. 2015;9(10):FC01-4.

19. Fletcher AP. Spontaneous adverse drug reaction reporting vs. event monitoring: A comparison. J R Soc Med. 1991;84:341-4.

20. Agu KA. Establishing pharmacovigilance system in a clinical setting. In: King RC, Oqua D, Agu KA, editors. GHAIN Pharmacovigilance for Antiretroviral Drugs Training for Healthcare professionals, Participants' Manual. Silver Spring, MD: DAS, Incorporated; 2009:71-85.

21. Kalaiselvan V, Prasad T, Vivek D, Singh GN, Rathore A, Rewari B. Integration of National AIDS Control Program and Pharmacovigilance Program of IndiaAntiretroviral Drugs safety coactions in India. Int $\mathbf{J}$ AIDS Res. 2015;02(4):37-8

22. Shanthi N, Chris D, Dennis F, Sten O. WHO Strategy for Collecting Safety Data in Public Health Programs, Complementing Spontaneous Reporting Systems. Drug Safety 2013;36(2):75-81.

23. Pal SN, Duncombe C, Falzon D, Olsson S. WHO strategy for collecting safety data in public health programmes: complementary spontaneous reporting systems. Drug Saf. 2013;36:75-81.

24. Rachlis B, Karwa R, Chema C, Pastakia S, Olsson S, Wools-Kaloustian K, et al. Targeted Spontaneous Reporting: Assessing Opportunities to Conduct Routine Pharmacovigilance for Antiretroviral Treatment on an International Scale. Drug Saf. 2016;39(10):959-76.

Cite this article as: Patil SV, Pawar SR. A retrospective study to evaluate the pattern of spontaneously reported antiretroviral induced adverse drug reactions in a tertiary care hospital. Int $\mathbf{J}$ Basic Clin Pharmacol 2018;7:828-32. 